\title{
Creating High-performing Innovation Teams
}

\author{
Mikael Johnsson \\ Blekinge Institute of Technology, Department of Mechanical Engineering, Karlskrona, Sweden \\ mikael · johnsson@bth.se
}

\begin{abstract}
This research suggests a conceptual process of how to create highperforming innovation teams to meet the market's need of faster ways of conducting innovation work. The CIT-process (Creating high-performing Innovation Teams) is a five-step-process systematically developed to meet organizational-, team-, and individual perspectives. On a holistic level, this research contributes to prior research by bringing research on innovation teams and high-performing teams together to become a pre-stage to established group dynamic processes and innovation processes. Practical implications and future research are suggested.
\end{abstract}

Keywords: High-performing, Innovation team, Group process, Teamwork, Multi-functional, X-functional, Product development.

\section{Introduction}

This research is based on the need for innovation teams with the ability to conduct agile innovation work within established companies. These teams are needed for two reasons: first, innovation is a key driver of economic growth and social development, that is, from national innovation systems to the underpinning regional growth strategies, and for organizational performance and competitiveness (Clark, 2012). To stay competitive, organizations must both continuously innovate their products (including services, processes, organizations, systems, etc.) to accommodate the rapidly changing environment (Brennan \& Dooley, 2005; Dobni, 2006; Tidd \& Bessant, 2013) and carefully manage their innovation processes (Dooley et al., 2000), and research shows that product life cycles have become shorter over time (Barczak et al., 2009); second, teams as such have for centuries contributed positively to work on innovation (e.g. Frostenson, 1997; Zuidema \& Kleiner, 1994), and several classifications of these teams have emerged over time: for example, "multifunctional innovation teams," "Xfunctional innovation teams" and "new product development teams" (NPD teams). Each has numerous positive effects based on the teams' performance: for example, decreased time to market (Highsmith, 2009), increased job satisfaction, reduced job stress, less time pressure (Cordero et al., 1998; McGreevy, 2006b), improved quality and productivity (McGreevy, 2006a), higher quality produced in a shorter time (Edmondson \& Nembhard, 2009). These teams enable knowledge sharing, the development of trust and the ability to overcome organizational barriers (Horth \& Vehar, 2012; Love \& Roper, 2008).

Innovation processes have also developed over time, from stage gates into cyclic innovation processes based on collaboration and iteration. Companies have to interact with customers, co-suppliers and both internal and external service providers to, for 
example, explore technological opportunities, build customer knowledge and networks, and co-develop with customers and partners to understand, visualize, and deliver value propositions (e.g. Berkhout et al., 2006; Narasimhalu, 2005; Smith et al., 2012; Tidd \& Bessant, 2013). Even though innovation processes are visualized over several steps or phases, the operational work can be divided in two phases. The early innovation phase centers on the ideas in focus (i.e. creative processes), while the later phase focuses on implementation (i.e. developing and marketing processes) (Amabile et al., 1996; Eschenbächer et al., 2011). Another practical approach to executing innovation work is to fail fast: that is, to make mistakes early and to try not to avoid failure. Instead, the idea is to fall forward, to learn from mistakes (Adkins, 2010; Tahirsylaj, 2012). Due to the level of abstractness in innovation work, methods of envisioning innovation processes act as knowledge agents, in terms of "knowledge integrators" and "knowledge brokers," to support innovation (Bertola \& Teixeira, 2003).

However, creativity and innovation processes are complex, and they depend on individual and group efforts from a divergence and convergence perspective (Backström et al., 2011; Haner, 2005). The complexity of innovation teams is also pointed out by Johnsson (2014), who claims that newly formed innovation teams hardly can handle all the complex work that they have to conduct without a proper set up when being created; that is, a newly formed innovation team needs to know, for example, how the innovation processes work, how to be creative when identifying new opportunities, how to execute practical innovation work, and how handle the group dynamic process.

In sum, there is a need to increase the speed of innovation work for organizations to stay competitive and to adapt to rapidly changing markets; innovation teams have proven to be a successful way of approaching innovation, as they generate great results; and well-researched innovation processes and practical tools exist for these teams. If the innovation team is successful, it will become a part of, and contribute to, increased innovation efficiency and thus become a high-performing innovation team. Still, what about organizations that are inexperienced in innovation work? Again, the innovation team is at the heart of this question, since it is supposed to conduct the practical work although the members of the organization may not be aware the complexity implied in innovation. As such, this research focuses on the deliberate creation of highperformance innovation teams.

\section{Literature review and research gap}

This section demonstrates a timeline of relevant research connected to the creation of high-performing innovation teams to demonstrate where and how the research focus has developed over time, closing with a clarification of the research gap and the research question that has guided the present study.

\section{$2.1 \quad$ High-performing innovation teams}

Research on groups and teams has been conducted for a long time, but the focus has rather been on groups or teams that have conducted innovation work or on innovation as a result of team work. Farris (1972) revealed that the setting of members in scientific 
groups effected performance of innovation. The group members within study were conducting R\&D work, but they separated their work in a collegial way over three stages - a suggestion stage, a proposal stage and a solution stage - to get input and support technical and administrative matters, for example. Farris found that highly innovative groups used supervisors to evolve original ideas rather than for the contribution of original ideas, and groups with influence on supervision were best for problem solving. Farris also suggested that the supervisor does not necessarily have to be innovative, which may in fact decrease the group's innovation performance, but the supervisor should offer support by encouraging the group to think through their technical problems and by playing an active part in the group, seeking original ideas from outside the group to spare the group from wasting energy on information collection but not imposing ideas on them.

In the 1980s, self-directed work groups (SDWG) were developed as a result of a buzzword of the day, "employee empowerment," and they had various names, for example "self-managed teams," "high-performance teams," "super-teams" or "crossfunctional teams" (Zuidema \& Kleiner, 1994). The teams consisted of three to 30 employees, but most often included six to 10 employees, and the idea was that groups were created to manage themselves to work on a specific work task. They were intended to have more flexible structures, to be cost effective, to overcome built-in bureaucracy, to speed up product innovation, to cut through hierarchical decision-making procedures and to respond quickly to changes in work conditions. The teams were considered Xfunctional, meaning that they would bring employees together from different departments to solve problems, for example with product development teams concentrated on innovation and development of cycles for new products. The benefits of this setting according to the team members were that they improved team involvement, morale and the sense of ownership of the team's goal, but mistrust of managers, conflicts between team members and stress syndromes caused from lack of familiarity with new situations were common. Management thought that improved quality, productivity and morale were the best outcomes. The conditions for successful SWDGs were that top management needed to believe in the approach and that the manager of the team should act like a coach or facilitator to develop consensus in the team. However, that required not only an overall change in attitude, but also trust building, the overcoming of fear-factors and appropriate training in new tools for employees and management.

In general, high-performing work teams were claimed, through the lens of the big five criteria, to be perform best when based on personal diversity (Neuman et al., 1999). In Neuman et al.'s study, the teams, which consisted of four people, were trained in all functions within the department, and the personalities traits of agreeableness, conscientiousness, and openness to experience were valid predictors of effectiveness, and team members with the traits of extroversion and emotional stability also improved performance. Furthermore, Neuman et al. suggests that the team members in a highly innovative team would need additional traits, such as creativity.

One way to create innovation teams is suggested by McDonough (2000): he proposes four factors that increase success for cross-functional teams; first, cooperation, that is, the importance of setting a common goal that every member understands; second, commitment, relating to the members' duty to achieve the goal and the fact that the 
members' skills, confidence, and willingness to commit themselves all contribute to making the project successful; third, ownership, that is, the desire to make change, which goes beyond commitment and requires a need for empowerment, climate, and goal setting early in project; fourth, respect, which is built on the feeling of trust, with which the members can interact honestly with each other, and thereby make cooperation possible.

In a study regarding NPD and the integration of other departments within the development work, Gomes et al. (2003) comes to the conclusion that early integration with marketing in the NPD process is beneficial. The higher the degree of interaction between R\&D and marketing in the stages of budgeting, planning and scheduling, the more collaborative the behaviors and attitudes of the people involved in NPD projects, which may aid in overcoming internal differences and other built-in barriers.

Pearce and Ensley (2004) suggest that the impact of shared vision on the innovation process is one of the main antecedents of effective team innovation, where they created teams based on managers or internal customers selected from interviews and questionnaires within a company. All participants were given at least 20 hours of training before the work began. The conclusion of the study was that a shared vision contributes highly to innovation efficiency. In addition, team potency, teamwork behavior, altruistic behavior, and courtesy behavior all increased within the study.

West et al. (2004) suggests that an innovative team could be developed within an organization in 12 steps. The first step is to identify the task, followed by identifying external demands, selecting the team members with a focus on skills and diversity, securing organizational rewards, creating a learning and development climate, fostering an atmosphere of innovation, establishing norms of innovation, encouraging reflexivity in teams (i.e. making them stop working for a while to reflect on the situation), ensuring that the team leader's style is appropriate, managing conflict constructively and aiming to bridge and coordinate competencies.

McGreevy (2006a; 2006b) offers a best practice for creating teams. From a practical point of view, he claims that one should start with gathering information on what teamwork is and how it effects the organization, followed by ensuring that top management is committed to the teamwork approach and that middle management is on the same track. The following steps plan for change of the culture and management structure, selecting team members based on applicability and willingness to develop the team. Furthermore, the team members should have management's approval and support to participate in the team, and they should be selected on an X-functional basis. In a longitudinal study between 2006-2010, an external innovation driver had positive effects on both the innovation project and the knowledge of innovation management within the participating innovation teams, according to Johnsson et al. (2010). The teams were created on a multifunctional basis, but the activities slowly decreased and completely stopped shortly after the project in two out of three participating companies due to lack of knowledge regarding innovation management.

Innovation steering groups (IS groups) were created by Hallgren (2009), who organized multifunctional IS groups that consisted of seven employees from "all levels," although top management was excluded to avoid their influence on the teams' decisions. The set 
up was that top management ensured their commitment to the IS group, then Hallgren taught the IS group to manage innovation by "learning by doing," and encouraged the rest of the company to be involved in the innovation project. The results of the innovation project were positive, overall, and the main reasons for positive results were attributed to the external innovation driver (Hallgren himself) and his stimulation of high involvement levels among the employees, accomplished by having group members choose an incremental idea by themselves. However, the IS groups lacked performance due to lack of innovation-related knowledge. In a 2009-2011 longitude study on the ability of innovation teams to increase innovation-related knowledge through seminars, inspired by IS groups in accordance with Hallgren (2009), it was found that employees inexperienced with innovation had problems with innovationrelated vocabulary, and innovation-related knowledge gaps caused problems not only for the teams but on the managerial level as well (Karlsson et al., 2010). Although the innovation teams had positive effects in terms of learning, there was mistrust of managers, conflicts between team members and stress from lack of familiarity with new situations (Johnsson \& Karlsson, 2011a).

Hülsheger et al.'s (2009) review of innovation team antecedents has identified two classes of antecedents as important to an innovation teams and their performance; team input and process variables and methodological moderator variables. The most influential factor for innovation was goal interdependence, and regarding team diversity it was found that job-related diversity was more important than personal diversity. Job-related diversity was slightly positive for innovation and had greater impact on performance than personal background. In fact, personal diversity showed a slightly negative relationship to innovation. Leadership was demonstrated to play an important role in organizing the potential for job-relevant diversity, that is, to stir up innovation by informing team members according to their different kinds of knowledge, skills, and capabilities, and helping them to value and use their different viewpoints to engage in elaboration and integration of opposing viewpoints. The team's size may effect the performance in two ways, as found by Hülsheger et al. (2009): if a team becomes too large it will suffer from social loafing, but if a large team has relevant knowledge, skills and abilities, it can handle difficult tasks, which may be the case for innovation projects. Team processes including vision, external communication, innovation support, task orientation, and internal communication have a strong correlation with innovation, meaning that managers and team leaders should strive to support these determinants by showing commitment and engagement. To foster innovation in the workplace, internal and external communication is especially important.

Barczak et al. (2009) conducted a study on NPD practices in order to identify what differentiates the best companies from the rest when portfolios are increasingly incremental and cycle times drop dramatically. They conclude that innovation processes are inherent to every company, but the best companies spend more effort on market research, engineering, $R \& D$, technology and team support. The suggested areas in which a company can improve its work are idea management, where formal processes are recommended; NPD project leadership and training; support of organizational mechanisms and processes in place for managing collaborations with other firms; the enabling of individuals with multiple functions to work together as a 
team; and support for team leaders from functional and senior managers.

Employee-driven innovation (EDI) is a result of the insight that human capital within a company has become increasingly important (Kesting \& Ulhöj, 2010). The concept of EDI is based on the assumption that employees at all levels have unrevealed capabilities for innovation and that these underutilized resources can be recognized and exploited to benefit both the organization and the employee. One major positive effect from EDI is that the employees' feel more motivated to work, but even though it was found that innovations can emerge in any department, from the shop floor to management, the team members' inexperience in decision making and bias hinders them from taking action in a project and thinking outside their ordinary routines. A similar concept to EDI is employees-driven innovation in a regular team (EDIT), developed by Kristiansen and Bloch-Poulsen (2010). The difference is that under this concept the team members could be anyone in the organization, regardless of educational background or current employment, a circumstance confirmed in practice by Kleinknecht (1987). Another difference from EDI was the researchers assisted the teams and their members, but instead of cooperating, the team members actively looked for shortcomings and pitfalls, questioning project agendas, complaining over long meetings about work overload and expressing skepticism. The researchers tried to solve these problems in separate meetings, where project planning was conducted.

Nakata and Im (2010) stress the question of whether cross-functional integration in NPD teams improves new product performance, and if that is the case, what the ways of strengthening this integration are. Their findings indicate that by letting high-tech companies assess the results of teams with divergent functions, cross-functional integration generates greater customer satisfaction, technological advancement and overall performance. They found that internal factors such as social cohesion and superordinate identity, and external factors such as market-oriented reward system, formalization of planning, and managerial encouragement to take risks are positively related with integration in NPD teams.

The only article identified within this literature review that addresses the creation of high-performing innovation teams is an academic course for teaching technological entrepreneurs how agile teamwork is conducted (Marion et al., 2012). The course is aimed at students who want to learn how to enter the market quickly with limited resources. The course includes the creation of multifunctional teams, where technical engineers work together with industrial design students. The program follows a structure where teams are created based on Meyer Briggs' personality trait classification, where type of engineer, background and experience determine to what team students will belong. The students have no influence on this grouping process, and 5-7 members typically form a team. A project manager is designated, and the team gets their scope to work on. The team has weekly meetings to review project deliverables and team progress, course work and assignments. At the end of the course, the team presents a concept, prototype, and technology to a panel of industry experts and investors. Two main success factors are identified within this course: first, the engineering and visualization students cooperate; second, the students use a very experimental approach. 
Recent research from Im et al. (2013) combines the two parts of innovation work, that is, creativity and implementation, as defined by Amabile et al. (1996), to explore the antecedents and consequences of creativity in product innovation teams. They conclude that antecedents to product innovation teams, that is, cross-functional teams, are social cohesion of both on internal- and external dynamics, as they have positive impacts on both new products and marketing programs. Internal dynamics, on the other hand, are defined as the emotional factors: to know one another, to be aware of the same kinds of opportunities, to have access to the same kinds of resources, and to share the same kinds of perceptions. The external dynamics are the organizational design and structure. Similar to prior research, Im et al. (2013) emphasize top management support and encouragement in establishing the meaningfulness of the innovation work and taking risks, but one of the key management tasks is to remove communication barriers to avoid conflicts, and when it comes to development teams, it is suggested that a kickoff may be important in building team identity.

Recent research from Johnsson (2014) suggests the innovation team model (ITM), where the complexity of the innovation team and its context are demonstrated to better understand the situation of a newly formed innovation team before innovation work has begun. The difference from the prior research on innovation teams is that ITM focuses on the highly complex situation that an innovation team, with inexperienced team members, will meet when its members start conducting its innovation work, that is, the management of innovation-related knowledge and associated knowledge gaps, innovation-related information flow and innovation awareness. In accord with prior research, the innovation team is created on the understanding that multifunctional teams perform better than individuals. One of the team members is suggested to be a convener to distribute the leadership to the other team members. The suggested steps in ITM are that the convener carefully choses the other team members based on their skills and personality.

\subsection{The research gap}

The literature affirms that teams have positive effects for companies' product development. Furthermore, multifunctional teams are more efficient than other teams, and the literature highlights an interest in what kinds of team members an innovation team should consist of. There is also a clear research focus on what factors are antecedent to successful innovation work within companies. Recently, creating innovation teams where employees from all levels within a company can contribute to innovation work has come into focus, and even though this team composition has met with positive results, obvious problems have also arisen in the teams. Problems identified in the present research on innovation teams (IS groups and EDITs) are mistrust of managers, conflicts between members and stress (Johnsson \& Karlsson, 2011a; Kristiansen \& Bloch-Poulsen, 2010 Johnsson \& Karlsson, 2011a;). These problems are interesting, since they were observed already in work on SWDGs in the 1980s (Zuidema \& Kleiner, 1994). Other recent problems related to innovation teams include that team members complain over long meetings about work overload and express skepticism (Kristiansen \& Bloch-Poulsen, 2010). Even though research clearly shows that the team leader should know about the group process (Adkins, 2010, Hallgren, 2009; West et al., 2004), there have been problems related to group dynamics 
causing the innovation project to struggle, that is, wasting valuable time and energy. One reason for such struggle might be that there is no time to create these kinds of teams in a proper way (Edmondson, 2012), but when reviewing the structured ways of creating innovation teams, there is a lack of focus on how to prevent the problems that arise in the development of the group.

It has been shown that multifunctional teams are more effective for NPD (e.g. Nakata \& Im, 2010), and it is stated that the work cycle in innovation work has been dramatically shortened (Barczak et al., 2009), but lack of innovation-related knowledge result in poor performance (Hallgren, 2009; Johnsson et al. 2010; Kesting \& Ulhöj, 2010).

Prior research into methodologies for how to create high-performing innovation teams to conduct innovation work in organizations has not yet been identified, nor methodologies for how to create innovation teams. However, McDonough (2000) and West et al. (2004) both suggest how to develop innovative teams, and McGreevy (2006a; 2006b) how to develop teams that perform. Marion et al. (2012) focus on how to create innovative student teams within engineering education. Johnsson (2014) is the only one who focuses on the complexity of innovation work and has developed a model that demonstrates the creation of innovation teams in a few steps within an organization. Still, they do not explicitly focus on how to ensure that the teams become high-performing innovation teams, but rather teams with potential innovation outcomes.

The literature suggests that research has come closer to the core of the creation of highperforming innovation teams, but there is still no explicit process demonstrating in how to do so. Prior research focused either on innovation teams or on high-performing teams, not putting these aspects together to create high-performing innovation teams. Another problem identified within the literature review is that groups and teams seems to be confused as being the same, but they are not, according to Wheelan (2013). It takes approximately six to eight months of teamwork for a group to become a highperforming team. However, only $15 \%$ reach that level, and as many as $80-90 \%$ of teams have performance problems within the emergence process. The problem is even greater for teams based on diverse members, which makes the creation of high-performing innovation teams a delicate task to fulfil, since innovation itself is highly complex.

To help to bridge the research gap, this research focuses on the pre-stage of innovation teams' emergence process, that is, on generating knowledge of how to create innovation teams so that they can enter the high-performing phase from the beginning.

\subsection{Research question}

Based on the introduction and problem identification, a research question emerged to guide this research: What would a conceptual process that demonstrates how to create a high-performing innovation teams look like?

The aim of this research is to generate new knowledge, to be demonstrated as a conceptual process, of how to create, step-by-step, high-performing innovation teams that waste neither time nor energy on conflicts or other non-valuable actions. 


\section{Research methodology and findings}

\subsection{Research methodology}

This research is inspired by the Design Research Methodology (DRM) approach (Blessing \& Chakrabarti, 2009), and the work has been conducted according to the first three stages of the DRM model: the research clarification, in which the research problem is defined and a research question is stated, followed by a descriptive study in which understanding is provided and developed within the prescriptive study stage into a process describing how to create high-performing innovation teams. The final descriptive study in the DRM model is not a part of this research (i.e. to evaluate the outcome of the suggested process), but presents a step to be taken in research.

This research was conducted systematically, where the first step was to explore prior research on high-performing innovation teams to understand the research area and the academic problem, partly through database research and partly as snowballing from relevant articles. Keywords such as "innovation team," "high-performing," "team," "group," "group members" and "how groups emerge and develop" were used when searching for relevant research. The database search engine Summon was used within this research, which cuts through multidisciplinary databases relevant for this research and is used in scholarly research worldwide. The literature was systemized and analyzed in the light of demonstrated methodologies concerning how to create innovation teams and whether they focused on group development problems. The conclusion was that prior research focused on either innovation teams or on highperforming teams; that is, the focus was mainly on the performance of teams' work, where innovation was a plausible output; creating a climate to stimulate innovation where teams and teamwork were highly supported ingredients; and the team members in terms of personalities and skills to perform as effectively as possible that could generate innovative output. However, research did not focus on creating highperforming innovation teams specifically, even though researchers agree on the need for faster ways to conduct innovation work.

As the research gap was clarified, a literature study was conducted to gather relevant data covering the organizational, team, and individual aspects of innovation, including team creation, group dynamics and psychology, and change management. To collect data for the theoretical framework, the database search engine Summon was used, which covers relevant research of this topic.

Finally, a conceptual process for creating high-performing innovation teams was developed and demonstrated step by step. In doing so, the data was first organized in organization, team and individual perspectives, and then it was clustered into themes by searching for patterns and connections relevant when creating innovation team (Boyatzis, 1998). This analysis yielded three main areas: management, including top management and middle management; team leadership; and team members; The second step was to identify phases, specific factors, processes and sub-processes relating to each other within the identified themes, which were used to develop a structure of a new process and theory (Blessing \& Chakrabarti, 2009; Boyatzis, 1998; Langely, 1999). This strategy resulted in a five-step process, the creating highperforming innovation teams (CIT) process, that on a conceptual basis demonstrates 
how to create high-performing innovation teams. The development of the CIT-process accorded with current innovation processes (e.g. Andersson, 1996; Johnsson, 2009; Tidd \& Bessant, 2013) subject for discussion with stakeholders, such as researchers, practitioners, small-and-medium enterprises (SMEs) and large industrial companies, to get feedback on its academic relevance and potential for both future research and practical application.

\subsection{Findings}

Based on the findings, a process in five steps emerged when aiming to create highperforming innovation teams. The approach of the CIT-process is to be similar to a guideline or a hands-on tool, as suggested by Dobni (2006), where the purpose is to ease organizations' efforts to create innovation teams that do not suffer from groupemergence-related problems or innovation-related knowledge problems.

\section{Creating high-performing innovation teams, the CIT-process.}

- Secure commitment from management, including top management.

- Identify an innovation team convener.

- Prepare (prime) the convener.

- Gather innovation team members.

- Kick-off innovation project.

Securing top managements' commitment

First, secure commitment from management, including top management. This step is crucial if one wants the planned innovation work to be official; otherwise one can skip this step and create an "under-the-radar innovation team" that conducts skunk work. However, as research claims that companies need to become more innovative in their approach, it is worth the effort to align management with the mindset of agile innovation work. In this first step, management needs information on how the innovation work will be conducted by the innovation teams, that is, step-by-step explanation of the CIT-process. One hurdle to pass in this initial step is to convince top management and management that unknown factors are a part of the usual innovation work to handle, and another hurdle may be to see innovation work as investment instead of risk. Depending on how innovationally mature the organization is (i.e., where they are on the industrial to post-industrial scale), the time for top management to see the benefits of high-performing innovation teams may vary, and one should not be surprised if it takes months to come to an agreement to set up a pilot project. Some argue that pilots are used to dismiss a new idea or process later on, but others actually use pilots for real evaluation and improvement. To gain the feeling of ownership and control at the management level, they can point out strategically important directions to work on, which also helps the creation of high-performing innovation team, as it is subsequently much easier to find appropriate team members;

\section{Identifying an innovation team convener}

Second, identify an innovation team convener. Management, together with the facilitator if needed, selects the convener. This second step is related to team leadership, but the convener is not to lead the team but to ensure that the innovation team is leading itself. If the convener can contribute to the innovation work, this contribution is a bonus, 
but it is not crucial for the selection. It is more important that the convener has the ability to see the benefit of the innovation organization work in the same way as management and has the ability to steer an innovation project to the goal together with the prospective team members. The convener's role is to create a small organization that is built on convergence and divergence, in which the members can feel that they become one unit and share leadership as a team. There is no project manager in the high-performing innovation team; all the prospective team members will be experts within their area, and they will with that development lead any part of the innovation project that relates to their expertise. Together, the team will take united ownership and management responsibility for the progress. The main task for the convener is to focus on the working environment and ensure the team works together on a consensus basis, helping and supporting each other in the shifting and challenging innovation work. In this work, as with the previous work, patience is important. It takes time to find the right person and time to secure this person's manager's support for participating in the high-performing innovation team. One can assume that at least $10 \%$ working time is needed, and in some parts of the innovation project even more time is needed.

\section{Preparing the convener}

Third, prepare or prime the convener. As soon as the convener is identified and has accepted the challenge of creating the planned high-performing innovation team, the previous work conducted with top management and management to build confidence in the forthcoming innovation work starts over again with the convener in focus. The purpose of priming the convener is to prepare that person for group process problems and cyclic innovation processes and to feel secure when the innovation project suddenly finds a new way towards the goal, which is not yet fully decided. Another task that the convener must prepare for is the challenges of transferring the method of conducting innovation work in an autonomous innovation team, where shared leadership is the key. Here, the facilitator can support with in-depth knowledge concerning how to think when choosing team members based on multifunctionality, how to conduct agile innovation work with guidelines and tools for the different steps in the innovation process, and how to communicate the need for individuals' responsibility and the importance of commitment. In sum, the convener has only an innovation direction to aim for, and based on that the convener starts to think of possible team members, how to conduct a kick-off and how to get the group to become a team instantly. In this part of the priming, it is important to focus on building the convener's self-confidence, since the more input the convener gets, the more complex the situation is to master.

\section{Gather team members}

Fourth, gather innovation team members. This step is one of the most critical, as one of the ground rules is that the high-performing innovation team is built on team members' trust in each other, trust in the sense that, for example, agreed upon work is executed and completed in time and that the commitment one feels in the beginning something new does not fade away. Therefore, the convener must carefully choose team members that fit the purpose, and the convener should not be surprised if this selection takes one or two months to accomplish. One reason for this timeline is that if a person is invited and accepts the invitation, that person should not be terminated from team. Here, the previous process of explaining the overall methodology is a now the convener's tool when inviting team members to be the core of the high-performing 
innovation team. As mentioned, a high-performing innovation team is based on multifunctionality, where at least one member should have connection to the organization's market. The other members' functions depend on the innovation project, but in total the team is preferably no bigger than four to six core members, including the convener. When searching for team members, the convener should define what core competences could be essential to the innovation project and choose to invite members in accordance with those competencies. It is essential to identify key people within these specific areas who want to participate and are open to new ways of working, since these key people are trusted, they have self-confidence, they have established networks and can easily connect to new networks when needed, and they can find help with specific tasks in the innovation project. Two critical aspects regarding time must be considered when selecting the key people: first, the key person must have available time to work in the innovation team, that is, real time available, not "I-can-get-it-donesomehow-time"; second, the key person's manager must approve that the invited person can work in the innovation project. Both of these aspects present problems later on if not addressed in a serious way during selection of the team members. Otherwise, the effect may be that the innovation project starts, but suddenly no one is doing the practical work. The high-performing innovation team is not supposed to do all the work by themselves, but to involve colleagues on temporary basis that conduct specific tasks along the innovation project. So, the required work time is about $10 \%$ for each member, but the situation for the team members will be the same as for the convener, that is, there will be occasions where less or more time is needed.

Kick-off

Fifth is the innovation project kick-off, the final step in preparation and the first step in the practical innovation work. The kick-off is the occasion on which the highperforming innovation team is officially created and initiated. Again, the overall methodology is explained to the team members, including the expected problems, from group emergence to how agile innovation work is conducted. This overview demonstrates that there will be tough situations to handle, but also that they have already been considered. The team members may not have met each other before, which is one challenge to handle; therefore, the team starts by establishing ground rules, expectations and a goal for the innovation project. Here, the facilitator can help by supporting with in-depth knowledge of group dynamics and with team-building exercises to provide the first hands-on tools to get the practical innovation work going. By this work, the team members are primed in a similar way as the convener, manager and top management; that is, the methodologies for why the innovation team has been created as it is have been approved at all levels and by the individuals concerned. With this preparation, the innovation team may be ready to start in a high-performing mode without waste of time and energy. A high-performing innovation team may have been created.

\section{$4 \quad$ Discussion and conclusion}

\subsection{Discussion}

Creating high-performing innovation teams, the CIT-process 
As demonstrated above, the suggested CIT-process is step-by-step process that begins with the top management's approval and ends with a kick-off. Below, the CIT-process is discussed from a theoretical perspective.

The CIT-process starts with approval from top management (Dobni, 2006; McGreevy, $2006 \mathrm{~b}$ ) or management that can make the decision to create a high-performing innovation team. This first step requires patience, as top management might need several months to adopt a new mind-set, or because the wanted commitment may be easily changed out of mistrust (Johnsson \& Karlsson, 2011b), delaying the CITprocess. In accordance with Backström et al. (2011), the organization itself must be mature enough to embrace new ways of working, or this moment is easily mired in a catch-22 based on the uncertainty connected to innovation work. To set up a project team to conduct an ordinary project is far different from creating a team to produce innovative results because the context is much more complex in terms of, for example, acquired innovation-related knowledge (Johnsson, 2014). The creation of a highperforming innovation team equals change; that is, the organization has to change to some degree to be able to conduct innovation work in a new way, and the new innovation team needs back-up and support from its management (Gamatese \& Hallowell, 2011; Hayton, 2003; Hayton \& Kelly, 2006; Kihlbom, 2005; RibieroSoriano \& Urbano, 2010; Un et al., 2010; West et al., 2003) and needs space and empowerment (Ahmed, 1998; Backström et al., 2011; 1998, Brown, 2005, West et al., 2004) to become high-performing.

Top management should ensure that innovation projects get necessary support from all levels in an organization, that structured methodologies and systems are set and that middle management at all levels is committed to the use of teamwork (Ahmed, 1998; West et al., 2004). Another task for the management, in general, is to encourage risk taking (West et al., 2004) and learning from mistakes rather than establishing blame (Aagard \& Gertsen, 2011).

Even though empowerment and autonomy are required for successful teamwork, it is also suggested that management provide a newly formed innovation team with direction for the innovation work (Hallgren, 2009, Tidd \& Bessant, 2013). However, the innovation team must feel free to conduct the innovation work in a way that is not too structured.

Except for the commitment of top management and middle management at all levels, team leadership has a central role in the high-performing innovation team. Prior research has shown that an innovation team leader must be well experienced with group processes and able to encourage team members to mature into a cohesive unit (Hallgren, 2009; West el al, 2004), and that involving inexperienced employees in innovation work is good for innovation in an overall and long term perspective (Bessant, 2003; Xu et al., 2006). Despite that, innovation teams created in that way have demonstrated group development related problems and innovation-related knowledge problems (Hallgren, 2009; Johnsson, 2011; Johnsson et al., 2010; Kesting \& Ulhöj, 2010; Kristiansen \& Bloch-Poulsen, 2010). External innovation drivers have been successful for innovation project performance (Johnsson et al., 2010; Hallgren, 2009), but the learning components are not thus fulfilled to enable the innovation teams to work on their own. To address these problems, the CIT-process suggests that the innovation team leader or innovation team manager be replaced for an innovation team 
convener. The person suitable to become a convener understands the importance of group processes (Hallgren, 2009; West et al., 2004) and plans for shared leadership (Adams, 1996, Backström et al., 2011, Trott, 2012). The convener should also have the ability to understand and set up an innovation teamwork environment (Johnsson, 2014) where the team members are motivated and self-confident (West et al., 2004), not feeling the threat of exclusion from the team (Wheelan, 2013), and the convener must for example participate, support the team and allow team members to make own decisions (Backström et al., 2011; Byrne et al., 2009; West et al., 2004), striving to help the members freely contribute to innovation (Dobni, 2006; Hallgren, 2009; Pearson, 2002; Xu et al., 2006). The convener understands the positive and critical effects of a broad representation of functions (Kelly, 2005). From an organizational perspective, the innovation convener also has support from innovative organization theory in the way that modern highly innovative organizations are built upon consensus and shared leadership (Laloux, 2014).

To avoid the group process problems demonstrated by, for example, Tuckmann and Jensen (1977) and Wheelan (2013) and experienced in prior research, the main idea of the CIT-process is to aim for shared leadership early, when planning for the creation of a high-performing innovation team. Accordingly, the convener should be educated in innovation management in general, in the basics of innovation teams, in how to select team members and to get commitment from their managers, in group dynamics and in how to manage the innovation model in practice. However, the convener must also be supported by his or her managers and be allowed the time to use a "learning-by-doing" approach (Hallgren, 2009; Johnsson et al., 2010) to overcome problems (O'Reily \& Pfeffer, 2000; von Hippel \& Tyre, 1995). This approach allows conveners to acquire their own understanding of aims and visions (Kihlbom, 2005).

The preparation and education should be provided by a person with experience from all these areas (Hallgren, 2009; Johnsson, 2014; Johnsson et al., 2010; Nanda \& Singh, 2009), and the suggestion within the CIT-process is that this person act like a facilitator to the convener and the innovation team until they are able to manage by themselves; that is, innovation work differs from ordinary work activities in that innovation work has the purpose of contributing to something new. Innovation models have been well described in several schematic models in recent decades (Andersson, 1996; Baxter, 2002; Johnsson, 2009; Michanek \& Breiler, 2004; Ottosson, 1999 Tidd \& Bessant, 2009) and further described for professionals (Adair, 2004; Utterback et al., 2006; Johansson, 2005; Johnsson, 2009; Kelly, 2001; King \& Anderson, 2002). However, the literature has not handled the potential to release untapped innovation capacity from ordinary employees' work activities, and this is where the facilitator is suggested to support the convener and the innovation team with practical advice (Hallgren, 2009; Johnsson et al., 2010) in accordance with a blended-learning approach.

The first assignment of the convener is to identify the team members and their managers to get approval to spend time on the innovation work (Hallgren, 2009). When selecting members, the big five criteria are important to keep in mind, that is, to have members that are, for example, organized, reliable, ambitious, hardworking, helpful, cooperative, sociable, enthusiastic, optimistic, calm, stable, curious, imaginative, broad-minded, and sophisticated. Furthermore, the people should be receptive to new influences and new 
knowledge and enjoy working together in a team. LePine et al. (2011), who have conducted research based on the big five developed by Barrick and Mount (1991), come to the conclusion that the selection of team members must be taken seriously, as one person who does not satisfy these criteria can have a negative effect on the work of the entire team, eventually ruining the project (LePine et al., 2011). If the innovation team feels that the performance is not improving because of a certain person or certain people, a natural reaction is to try to exclude any counter-productive person from the team. Instead, however, the innovation team should focus on helping that person to increase the team's effectiveness (LePine et al., 2011; Wheelan, 2009).

The potential members' participation by free will is of importance (Hallgren, 2009; Hoegl et al., 2003; Nerkar et al., 1996; Xu et al., 2006), and Hallgren (2009) suggests that the idea to be developed should be the attractant for the team members, but one problem to be aware of is that most employees do not participate because of a perceived lack of time, resources and knowledge (Kesting \& Ulhöj, 2010). It is also important that the ideas follow or align with the overall strategy of the organization. Prior research has shown that small teams are more effective than larger teams, where the suggested number of members is three to eight, but the best-performing teams are of three to six members (Dew \& Hearn, 2009; Wheelan, 2009). Within the CIT-process, I suggest that a team is ready to launch an innovation project when the convener has gathered another two or three members to participate in the innovation team, as long as they cover or have access to market, suppliers and distribution (Andersson, 1999; Johnsson, 2009; Tidd and Bessant, 2013) and leave a few places to be used for temporary members. More than six members would probably cause social loafing (Aronson, 1999; Clark, 2003; Dew \& Hearn, 2009; Wheelan, 2009). Members of the team should have characteristics selected according to the big five, except for extroversion, since homogeneity on this characteristic allows a team to avoid conflicts regarding leader roles, according to LePine et al. (2011). However, the CIT-process follows the research of innovation models (Andersson, 1996; Baxter, 2002; Johnsson, 2009; Michanek \& Breiler, 2004; Ottosson, 1999; Tidd \& Bessant, 2009, 2013) where both an external and an internal perspective are important. By "external perspective" I mean active connections with, for example, end users, customers and suppliers, and by "internal perspective" I mean connections with other departments and an internal network containing relevant competences. The CIT-process also builds on shared leadership (Backström et al., 2011, Trott, 2012) why I believe that extroversion is a positive character for all members of the innovation team.

The innovation team should be multifunctional, so divergence and convergence should work as attractors of the members (Lubaktin et al., 2001). Divergence in, for example, skills and knowledge is positive for the dynamic of the group. It prevents group thinking, which in many cases produces incorrect decisions early in projects, and divergences in a network are also positive, as they make it easier to find relevant competences when needed (Isaksen \& Ekvall, 2010; Olsson et al., 2010).

Following LePine et al. (2011), the innovation team members should be open to learning new methodologies, but as the members are in a process of divergence and convergence, the individuals need to have reached readiness for learning (Billett, 2001; Ellström et al., 2007). The process of achieving learning readiness is dependent on the individuals and upon the organizational wish to engage in a certain of work (Ellström 
et al. 2007), in this case, innovation work. This eagerness relates to the ability to be aware of innovation affordances, that is, opportunities to innovate in everyday work or other situations. Norman (1999) claims that affordances are available everywhere at all times but must be detected. Affordances can be visible or perceived in a physical product or be invisible in a situation, for example, at a workplace, in the supermarket while shopping, in contact with a supplier or at a meeting with the innovation team. The ability to achieve innovation readiness in order to detect affordances requires practice, which is why the convener has to identify members open to learning related skills.

As claimed above, innovation is about change. In the case of innovation, change is most often connected to shifts in established work routines. In the same way, as it is suggested to prepare the convener to establish a good start, the CIT-process recommends that the entire innovation team start with a kick-off where the members can unite and start their development process (Amabile et al., 1996). Actually, in the CIT-process the group development process starts when the convener invites the team members to join the team and prepares them for the project in its entirety. This preparation eases the start up, as the members can become familiar with one another before the kick-off (Edmondson, 2012; Nanda \& Singh, 2009). At the kick-off, the main focus is to establish a team formation based on the unique situation of the innovation team (Olsson, 2010; Wheelan, 2013), meaning that they should set the agenda, establish goals, and find ways to start work and to communicate, meet and relate to each other; the most important thing is that all members actively agree on what they decide upon (Adkins, 2010; Backström, 2011). The role of the convener at the kick-off is to build trust and establish commitment (Johnsson \& Karlsson, 2011b, Lubaktin, 2001), which could be achieved by being honest about limitations and uncertainties, ensuring there are no hidden agendas, acknowledging ideas, and creating space for communication without filtering information between management and members. Another important element of the kick-off is to be explicit in the group dynamic process problems that might appear and how to handle them. Every member is thus prepared for what might come, making future situations easier to anticipate, handle and sort out (Wheelan, 2013). To support the convener at the kick-off, the facilitator plays the important role of preparing the team in the same way the convener was prepared (Hallgren, 2009; Kihlbom, 2005; Nanda \& Singh, 2009).

Time is required for involved people to develop their own understandings of what is happening and what will come (Kihlbom, 2005), to emerge as a team and to develop order parameters (Backström \& Olson, 2010). Once in a while, it can be valuable to remind top managers that the team members need time both to understand innovation work and to develop the team, especially as research shows that even, for example, top management needs around six months to understand the background necessary to start a shift towards an innovative organization (Karlsson et al., 2010), and six to eight months are needed to develop a high-performing team (Wheelan, 2013). Learning begins in the individual, continuing as group learning, performed via a dialog and discussions between the individuals. The final step is a system thinking that is shared by all concerned (Kihlbom, 2005). When interpreting this thinking in terms of the CITprocess, one can see the introduction of the top mangers, other managers, the convener and the gathering of team members as individual learning. The group learning starts at 
the kick-off, and system thinking is achieved when all members reach the critical level of understanding.

\section{CIT-process as a pre-stage to group processes}

As suggested in the previous section, the CIT-process is a step-by-step process that starts at the level of top management and ends with a kick-off. When looking at the CIT-process from that perspective, it could be seen as a pre-stage to established group dynamic processes as the group starts with a formative stage and hopefully reaches a team stage (Buijs, 2007; Tuckmann \& Jensen, 1977), or preferably a high-performing stage (Wheelan, 2013). Even though time is needed to prime and prepare the involved people, which may take months of work, one benefit is that this time effects only the convener, that is, one person and not the entire team of four to six people. Another benefit is that there commitment from the team members is secured at the kick-off, and they can start forming norms and discussing plausible issues that may cause conflicts from the very first day of the innovation project. That prepares the team for possible problems that may occur in the forthcoming work, thus saving both time and energy.

\subsection{Conclusion}

The CIT-process is a conceptual process that presents a step-by-step guide and structure to create high-performing innovation teams. It is developed from established research in relevant areas. On a theoretical level, the CIT-process provides guidance to organizations that aim for increased efficiency when developing new products (services, processes, etc.) as it may reduce time and energy for an innovation team to become high-performing.

The message of the suggested CIT-process is that one should not hope for an innovation team to reach the high-performing stage immediately nor to focus on tools to rescue innovation teams already struggling. Instead, one should carefully plan and prepare for a high-performing innovation team to be created in the first place. This planning is be accomplished by addressing both plausible group process problems and challenging uncertainty in innovation work, by priming and preparing involved people from top management to individual team members, by aiming for shared leadership when involving the convener and team members all the way to kick-off and, furthermore, by securing support from an experienced innovation facilitator that can, when needed, remind the convener and team members of the group-development challenges and planned uncertainty along the innovation project.

\subsection{Contribution to prior research}

This research contributes to prior research in several ways. On a holistic level, it contributes to group dynamic processes by suggesting a pre-stage to already established theories of innovation processes (e.g. Johnsson, 2009; Narasimhalu, 2005; Smith et al., 2012; Tidd \& Bessant, 2013). However, to be more specific, there are four main contributions to highlight. First, prior research has focused on either innovation teams or high-performing teams (Adkins, 2010; McDonough, 2000; McGreevy; 2006a; 2006b; West et al., 2004). This research contributes by joining these two branches together, resulting in a conceptual methodology for how to create not just any innovation teams, but high-performing innovation teams. Second, prior research has 
suggested that an innovation team consists of the team leader or an innovation driver to ensure that progress is achieved. The consequences are that the innovation teams suffer from lack of innovation-related knowledge. This research contributes by suggesting a setup based on an innovative organizational structure, where the innovation team leads itself based on shared leadership among the innovation team's members (Adams, 1996, Backström et al., 2011, Trott, 2012). Third, prior research conducted on innovation teams has revealed problems connected to performance caused by lack of innovation-related knowledge. This research contributes by suggesting a convener, and a facilitator if needed, to ensure that the innovation-related knowledge is provided to the team members. The facilitator ensures that management at all relevant levels is provided with adequate innovation-related knowledge. Fourth, prior research conducted on innovation teams has demonstrated problems connected to group emergence problems (Hallgren, 2009; Kesting \& Ulhöj, 2010; Kristiansen \& Bloch-Poulsen, 2010). Much research on innovation teams and group development has been conducted, but not focusing on the conditions for the creation of high-performing innovation teams, as this research has done (Buijs, 2007; Tuckmann \& Jensen, 1977; Wheelan, 2013). This research contributes suggestions for how to prevent the initially most problematic and challenging stages a newly formed innovation team confronts. The key element here is to enter the high-performing stage faster and more easily than before, where the suggested method is to secure the innovation project by ensuring commitment from all levels of the company, to carefully choose a convener, to invite team members that ensure their buy-in and to provide an understanding of the group dynamic process.

\subsection{Practical application}

The contention of the CIT-process is that an innovation team's success can be planned for in advance with proper preparation for a high-performing innovation team already on the drawing table. When focusing on providing solutions to already-known group process problems before the innovation team is gathered, as described above, the team has the potential to skip or minimize the initial challenges of the group process and start in the team, or even better, in the high-performing phase. Such efficiency would probably save much time, money, energy and effort for all involved people and parties. Businesses and innovation leaders may adopt this knowledge and suggest new ways of starting an innovation project within an organization, and the approach may be used to educate customers or clients on how to prepare an organization to become more agile, responding quickly with new ideas to meet the present market conditions. The practical contribution of this research would be to speed up innovation work and thus contribute to increased innovation efficiency concerning the total time for development, the implementation and the magnitude of the innovation, as stated by Pearce and Ensley (2004).

\section{$5 \quad$ Limitations of the study and suggestions for future research}

The suggested CIT-process is based on a theoretical framework, systematically developed to meet organizations increasing needs for faster ways of conducting 
innovation work. Although it is based on relevant research and best practices regarding, for example, innovation teams and group dynamic processes, there are limitations to be considered. One should notice that the CIT-process is a conceptual process and needs to be evaluated. Further, the CIT-process is designed to be applicable to organizations such as, for example, SMEs or large companies aiming to develop a more agile way of conducting innovation work. Another limitation is that it requires a knowledgeable person who can introduce it to an organization before it is adopted, as some elements of the CIT-process require a high level of innovation-related knowledge.

Suggestions for future research are to create case studies through which the CITprocess could be studied. The research focus would for example, concern how a facilitator effects the innovation team, the innovation team's development process and the team's performance. Measurable indicators would be to measure cost, time and intangible results and values from innovation projects, and to compare those results to how the company usually plans and conducts similar innovation projects. Of course, a study regarding whether an innovation team created in accordance with the CIT-process would be high-performing or not is highly recommended.

\section{References}

Aagard, A., Gertsen, F. (2011) Supporting Radical Front End Innovation: Perceived Key Factors of Pharmaceutical Innovation. Creativity and Innovation Management, 20(4), 330-346.

Adair, J. (2004). Adair on Creativity and Innovation. London: Thorogood Publishing Ltd.

Adams, R, Bessant, J., Phelps, R. (2006). Innovation management measurement: A review. International Journal of Management Reviews, 8(21), 21-47.

Adkins, L. (2010). Coaching Agile Teams: A Companion for ScrumMasters, Agile Coaches, and Project Managers in Transition. Massachusetts, Courier.

Ahmed, P.K. (1998). Culture and climate for innovation. European Journal of Innovation Management, 1(1), 30-43.

Amabile, T., Conti, R., Coon, H., Lazenby, J., Herron, M. (1996). Assessing the work environment for creativity. Academy of Management Journal, 39(5), 1154-1134.

Andersson, R. (1996). Uppfinnarboken - Om uppfinnandets innersta väsen (in Swedish). Malmö, Lieber-Hermods.

Aronson, E. (1999). The Social Animal. New York: Worth Publishers.

Arranz, N., de Arroyabe J.C.F. (2011). Can innovation network projects result in efficient performance? Technological Forecasting \& Social Change, 79, 485-497.

Backström, T., Olson, B.K. (2010). Kaikaku - a complement to emergence based development. Paper presented at the first ICDC Conference Kobe, Japan.

Backström, T., Wilhelmson, L., Åteg, M., Olson, B.K., Moström Åberg, M. (2011). The Role of Manager in the Post-Industrial Work System. In Studies in industrial renewal, edited by Segelod, E., Berglund. K., Bjurström, E., Dahlquist, E., Hallén, L., Johansson, L. Eskilstuna, Mdh Repro, 215-227. 
Balsamo, T.J., Goodrich, N.E., Lee, J.M, Morse, T.F., Roberts, D.A. (2008). Identify your innovation enablers and inhibitors. Industrial Research Institute. 23-33.

Barrick, M., Mount, M. (1991). The big five personality dimensions and job performance: A meta-analysis. Personnel Psychology, 44, 1-26.

Barczak, G., Griffin, A., Kahn, K. B. (2009). Perspective: trends and drivers of success in NPD practices: results of the 2003 PDMA best practices study. Journal of product innovation management, 26(1), 3-23.

Baxter, M. (2002). Product Design. Cheltenham, Nelson Thornes Ltd.

Belbin, M. (1993). Team Roles at Work, Butterworth Heineman, Oxford.

Berkhout, A.J., Hartmann, D.,Van der Duin, P., Ortt, R. (2006). Innovating the innovating process. International Journal of Technology Management, 34(3/4), 390-404.

Bertola, P. \& Teixeira, J.C. (2003). Design as a knowledge agent How design as a knowledge process is embedded into organizations to foster innovation. Design Studies, 24(2), 181-194.

Bessant, J. (2003). High-Involvement Innovation, Building and Sustaining Competitive Advantage Through Continuous Change. Wiley, Chichester.

Billett, S. (2001). Learning through work: workplace affordances and individual engagement. Journal of Workplace Learning, 13(5), 209-214.

Blessing, L., Chakrabarti, A. (2009) DRM, A Design Research Methodology. UK, Springer London Ltd.

Bossink, B. (2004). Managing Drivers of Innovation in Construction Networks. Journal of Construction Engineering and Management, 337-345.

Boyatzis, R.E. (1998). Transforming Qualitative Information: Thematic analysis and code development. USA, SAGE Publications Inc.

Brennan, A., Dooley, L. (2005). Networked creativity: a structured management framework for simulating innovation. Technovation 25, 1388-1399.

Brown, C. (2005). Empowering innovation: extending services regionally. World Patent Information, 27, 37-41.

Buijs, J. (2007). Innovation Leaders Should be Controlled Schizophrenics. Journal compilation, 16(2), 203-107.

Byrne, C.L., Mumford, M.D., Barret, J.D., Vessey, W.B (2009). "Examining the Leaders of Creativity Efforts: What Do They Do, and What Do They Think About. Creativity and Innovation, 18(14), 256-268.

Christensen, C. (1997). The Innovator's Dilemma, Boston, USA, Harvard Business School Press.

Clark, R. (2003). Fostering the Work Motivation of Individuals and Teams. Performance Improvement, 42(3), 21-29.

Clark, D. (2012). Innovation Management in SMEs: Active Innovators in New Zeeland. Journal of Small Business and Entrepreneurship, 23(4), 601-619

Cordero, R., Farris, G., DiTomaso, N. (1998). Technical Professionals in Crossfunctional Teams: Their Quality of Work Life. Journal of Product Innovation 


\section{Management, 15, 550-563.}

Denning, S (2011). Reinventing management: the practices that enable continuous innovation. Strategy \& Leadership, 39(3), 16-24.

Dew, R., Hearn, G. (2009). A new model of the learning process for innovation teams: Networked nominal pairs. International Journal of Innovation Management, 13(4), 521-535.

Dobni, C.B. (2006). The innovation blueprint. Business Horizons, 49, 329-339.

Dooley et al, (2000). Supporting Sytems Innovation. International Journal of Innovation Management, 4(3) 277-297.

Eales-White, R. (1997). Teambuilding: Att utveckla arbetslag (in swedish / Nilsson, B.), Lund, Studentlitteratur.

Edmondson, A., Nembhard, I.M. (2009). Product Development and Learning in Project Teams: The Challenges Are the Benefits. Journal of Product Innovation Management, 26, 123-138

Edmondson, A. (2012). Teamwork on the Fly. Harwards Business Review, August.

Ellström, E., Ekholm, B., Ellström, P.E. (2007). Two types of learning environment Enabling and constraining a study of care work. Journal of Workplace Learning, 20(2), 84-97.

Eschenbächer, J., Seifert, M., Thoben, K-D. (2011). Improving distributed innovation processes in virtual organisations through the evaluation of collaboration intensities. Production, Planning \& Control, 22(5-6), 473-487.

Farris, G. F. (1972). The effect of individual roles on performance in innovative groups. R\&D Management, 3(1), 23-28.

Feng, B., Jiang, Z-Z., Fan, Z-P, Fu, N. (2009). A method for member selection of crossfunctional teams using the individual and collaborative performances. European Journal of Operational Research, 203, 652-661

Frostenson, S. (1997). Fem kompententa team: Det lilla företaget i det stora företaget (in Swedish), Lund, Studentlitteratur.

Gamatese, J.A., Hallowell, M. (2011). Enabling and measuring innovation in the construction industry. Construction Management and Economics, 29, 553-567.

Gomes, J. F., de Weerd Nederhof, P. C., Pearson, A. W., Cunha, M. P. (2003). Is more always better? An exploration of the differential effects of functional integration on performance in new product development. Technovation, 23(3), 185-191.

Hallgren, E.W. (2009). How to Use an Innovation Audit as a Learning Tool: A Case Study of Enhancing High-Involvement Innovation. Creativity and Innovation Management, 18(1), 48-58.

Haner, U-E. (2005). Spaces for Creativity and Innovation in Two Established Organizations. Creativity and Innovation Management, 14(3), 288-298.

Hayton, J. C. (2003). Strategic human capital management in SMEs: An empirical study of entrepreneurial performance. Human Resource Management, 42(4), 375391.

Hayton, J.C., Kelly, D.J. (2006). A competency-based framework for promoting 
corporate entrepreneurship. Human Resource Management, 45(3), 407-427.

Hemphälä, J., Magnusson, M. (2012). Networks for Innovation - But What Networks and What Innovation? Creativity and Innovation Management, 21(1), 3-16.

Highsmith, J. (2009). Agile Project Management: Creating Innovative Products, Crawfordsville, Addison-Wesley.

Hoegl, M. (2005) Smaller teams-better teamwork: How to keep project teams small. Business Horizons, 48, 209-214.

Horth, D., Vehar, J. (2012). Becoming a Leader Who Fosters Innovation. Center of Creative Leadership.

Hülsheger,U.R., Anderson, N., Salgado,J.F.(2009). Team level predictors of innovation at work: a comprehensive meta analysis spanning three decades of research. Journal of Applied psychology, 94(5), 1128.

Im, S., Montoya, M. M., Workman, J. P. (2013). Antecedents and consequences of creativity in product innovation teams. Journal of Product Innovation Management, 30(1), 170-185.

Isaksen, S.G., Ekvall, G. (2010). Managing for Innovation: The Two Faces of Tension in Creative Climates. Creativity and innovation management, 19(2), 73-88.

Johansson, F. (2005). Medicieffecten (in Swedish). Stockholm, BookHouse Publishing $\mathrm{AB}$.

Johnsson, M. (2014). Innovation Teams: Before Innovation Work is Begun. Paper presented at the 25th ISPIM Innovation Conference in Dublin, Ireland.

Johnsson, M., Karlsson, H. (2011a). Existence of negative innovation-gaps affecting innovation performance in two Swedish SMEs. Paper presented at the $22^{\text {w }}$ ISPIM Innovation Conference in Hamburg, Germany.

Johnsson M., Karlsson, H. (2011b). External Innovation Driver (EID) - a Developing and Organization Learning Service in Innovation Management: Three cases where an EID develop and learn SMEs innovation management. IASPConference $X X V I I I$, Copenhagen, Denmark.

Johnsson, M., Ekman, S., Wiktorsson, M., Karlsson, T. (2010). A model-based process for developing environmental innovations: Four cases where the RAFT-model has been used in environmental innovations. IASP Conference XXVII Daedak, South Korea.

Johnsson, M. (2009). Sälj skinnet innan björnen är skjuten (in Swedish). Östertälje, Östertälje tryckeri

Karlsson, H., Johnsson, M., Backström, T. (2010). Interview Supported Innovation Audit: how does a complementary interview affect the understanding of an innovation audits results when the interview is based on the audit statements. Paper presented at the 3 ISPIM Innovation Symposium in Quebec, Canada.

Katzenbach, J., Smith, D. (1993). The wisdom of teams : creating the high performing organization. Harward business school press.

Kelly, T. (2001). The Art of Innovation. New York, Random House.

Kelly, T. (2005). Ten faces of Innovation. USA, Broadway Business. 
Kesting, P., Ulhöj, J.P. (2010). Employee-driven innovation: extending the license to foster innovation. Management Decision, 48(1), 65-84.

Kihlbom, G. (2005). Släpp medarbetarna loss (in Swedish). Malmö, Lieber-Hermods.

King, N., Anderson, N. (2002). Managing Innovation and Change: A Critical Guide for Organizations, London, UK, Thomson.

Kleinknecht, A. (1987). Measuring R and D in Small Firms: How Much Are We Missing? The Journal of Industrial Economics, 36(2), 253-256.

Kristiansen, M., Bloch-Poulsen, J. (2010). Employee Driven Innovation in Team (EDIT) - Innovative Potential, Dialogue. International Journal of Action Research, 6(2-3), 155-195.

Laloux, F. (2014). Reinventing Organizations. A Guide to Creating Organizations Inspired by the Next Stage of Human Consciousness.

Langley, A. (1999). Strategies for theorizing from process data, Academy of Management Review, 24(4), 691-710.

Lans, H. (1997). Uppfinn framtiden (in Swedish). Nynäshamn, Malms Repro.

LePine J.A., Buckman, B.R., Crawford, E.R., Methot, J.R. (2011). A review of research on personality in teams: Accounting for pathways spanning levels of theory and analysis. Human Resource Management Review, 21, 311-330.

Love, J., Roper, S. (2009). Organizing innovation: Complementarities between crossfunctional teams. Technovision, 29, 192-203.

Lubaktin, M., Florin, J., Lane. P. (2001). Learning together and apart: A model of reciprocal interfirm learning. Human Relations, 54(10), 1353-1382.

Marion, T. J., Friar, J. H., Cullinane, T. (2012). A Multi Disciplinary New Product Development Course for Technological Entrepreneurs. Journal of the Academy of Business Education, 13.

McDonough III, E.F. (2000). Investigation of Factors Contributing to the Success of Cross-Functional Teams. Journal of Product Innovation Management, 17(3), 221235.

McGreevy, M. (2006a). Team working: part 1 - an evaluation of current thinking. Industrial and commercial training, 38(5), 259-264.

McGreevy, M. (2006b). Team working: part 2 - how are teams chosen and developed. Industrial and commercial training, 38(7), 365-370.

Michanek, J., Breiler, A. (2004). Idéagenten - en handbok i idea management (in Swedish). Jönköping, Brain Books AB.

Nakata, C., Im, S. (2010). Spurring Cross Functional Integration for Higher New Product Performance: A Group Effectiveness Perspective. Journal of Product Innovation Management, 27(4), 554-571.

Nanda, T., Singh, T.P. (2008). Determinants of creativity and innovation in the workplace: a comprehensive review. International Journal of Technology, Policy and Management, 9(1), 84-106.

Nerkar, A.A., McGrath, R.G., MacMillan, I. C. (1996). Three Facets of Satisfaction And Their Influence On The Performance Of Innovation Teams. Journal of Business Venturing, 11, 167-188. 
Neuman, G. A., Wagner, S. H., Christiansen, N. D. (1999). The relationship between work team personality composition and the job performance of teams. Group \& Organization Management, 24(1), 28-45.

Norman, D.A. (1999). Affordance, conventions, and design. Interactions, 6(3), 38-41.

O'Reily, C., Pfeffer, J. (2000). Hidden Value: How Great Companies Achieve Extraordinary Results with Ordinary People. Boston, Harvard Business School Press.

O'Reilly, C.A., Tushman, M.L. (2004). The Ambidextrous Organization. Harvard Business Review, 82, 74-81.

OECD (2005). Oslo Manual - Guidelines for Collecting and Interpreting Innovation Data.

Olsson, A., Wadell, C., Odenrick, P., Norell Morgendahl, M. (2010). An action learning method for increased innovation capability in organisations. Action Learning: Research and Practice, 7(2), 167-179.

Ottosson, S. (1999) Dynamisk Produktutveckling (in Swedish). Floda, Tervix AB.

Pearce, C. L., Ensley, M. D. (2004). A reciprocal and longitudinal investigation of the innovation process: The central role of shared vision in product and process innovation teams (PPITs). Journal of Organizational Behavior, 25(2), 259-278.

Pearson, A. E. (2002). Though-Minded Ways to Get Innovative. Harvard Business Review, 80(8) 117-124.

Ribeiro-Soriano, D., Urbano, D. (2010). Employee-organization relationship entrepreneurship: an overview. Journal of Organizational Change Management, 23(4), 349-359.

Smart, P., Bessant, J., Gupta, A. (2007). Towards technological rules for designing innovation networks: a dynamic capabilities view. International Journal of Operations \& Production Management, 27(10),1069-1092.

Smith, S., Smith, G., Shen, Y-T. (2012). Redesign for Product Innovation. Design Studies, 33(2), 160-184.

Tahirsylaj, A.S. (2012). Stimulating creativity and innovation through Intelligent Fast Failure. Thinking Skills and Creativity, 7, 265-270.

Tidd, J., Bessant, J. (2009). Managing Innovation, fourth edition. West Sussex: John Wiley \& Sons Ltd.

Tidd, J., Bessant, J. (2013). Managing Innovation, fifth edition. West Sussex, John Wiley \& Sons Ltd.

Tillväxtverket (2014). Definition of large company. Accessed 11th May 2017. Available at: http://www.tillvaxtverket.se/huvudmeny/insatserfortillvaxt/flerochvaxandeforeta $\mathrm{g} /$ cosme/eusdefinitionavsmfsme.4.21099e4211fdba8c87b800017125.html.

Trott. P. (2012) Innovation Management and New Product Development, Fifth edition. Essex, Pearson Education Ltd.

Tuckmann, B.W., Jensen, M.A.C. (1977). Stages of Small-Group Development Revisited. Group and Organization Management, 2, 419-427. 
Un, A.C., Montoro-Sanchez, A. (2010). Innovative capability development for entrepreneurship: A theoretical framework. Journal of Organizational Change Management, 23(4), 413-434.

Utterback, J.M, Vedin, B-A., Alvarez, E., Ekman, S. (2006). Design-Inspired Innovation, London, World Scientific Publishing.

Vandenberg, R.J., Richardson, H.A., Eastman, L.J. (1999). The impact of high involvement work processes on organizational effectiveness: A second-order latent variable approach. Group \& Organizational Management, 24(3), 300-339.

Vinnova (2012). Innovationsledning och kreativitet $i$ svenska företag (in Swedish). Edited by Richtner, A., Frishammar, J. Sweden, Edita.

Von Hippel, E., Tyre, M. (1995). How "Learning by Doing" is Done: Problem Identification in Novel Process Equipment. Research Policy, 1-12.

West, M., Hirst, G., Richter, A., Shipton, H. (2004). Twelve steps to heaven: Successfully managing change through developing innovative teams. European Journal of Work and Organizational Psychology, 13(2), 269-299.

Wheelan, S. A. (2009). Group Size, Group Development, and Group Productivity. Small Group Research, 40(2), 247-262

Wheelan, S. A. (2013). Creating Effective Teams - A Guide for Members and Leaders. Lund, Studentlitteratur AB

Xu, Q., Chen, J., Xie, Z., Liu, j., Zheng, G., Wang, Y. (2006). Total Innovation Management: a novel paradigm of innovation management in the 21 st century. Journal of Technology Transfer, 32, 9-25.

Zuidema, K.R., Kleiner, B.H. (1994). Self-directed work groups gain popularity. Business Credit, 96(9), 21-26. 